\title{
Ciberativismo negro feminino no Instagram: as atividades da rede social em prol da prática antirracista durante a pandemia de covid-19
}

\author{
Luciana Priscila Santos Carneiro ${ }^{\mathrm{i}}$ \\ Vanessa Riambau Pinheiro ${ }^{\mathrm{ii}}$
}

\begin{abstract}
RESUMO
O presente trabalho objetiva analisar o ativismo virtual de personalidades ativas no Instagram, em prol da prática antirracista no período pandêmico, no ano de 2020. Como processo metodológico, verificaremos seus discursos, por meio das postagens feitas em maio, junho e julho de 2020, período em que as discussões contra o racismo explodiram nas redes sociais. As publicações escolhidas para a nossa análise são direcionadas, principalmente, a como e por que exercer essa prática. Utilizaremos, como aporte teórico, os conceitos de cibercultura (LEMOS, 1997) e ciberativismo (RESENDE et al., 2015). Por meio deles, confirmamos que escritoras como Djamila Ribeiro, Lívia Natália e Luana Genot utilizam o Instagram como ferramenta de expansão de suas reflexões e debates sociais. As três escritoras aqui citadas, além de muitas contribuições sociais fora do universo virtual, em suas publicações no Instagram, atuam como ativistas das mulheres e do corpo negro e fomentam discussões que se espalharam pelo mundo virtual, atingindo o mundo real, analisando fatos, falas e comportamentos a partir do viés antirracista, chamando a sociedade como um todo para a reflexão, contribuição e participação efetiva na luta contra o racismo.
\end{abstract}

Palavras-chave: Antirracismo; Rede sociais; Instagram.

\begin{abstract}
This paperwork aims to analyze active personalities' virtual activism on Instagram, in favor of an antiracist practice on the pandemic period, in the year of 2020. As methodological process, we are going to verify their discourse, through posts made between May and July of 2020, period of time in which discussions against racism have exploded on the social networks. Using the concepts of cyber culture (LEMOS, 1997) and cyber activism (RESENDE et al., 2015), we confirmed that writers such as Djamila

\footnotetext{
i Doutoranda pelo Programa de Pós-Graduação em Letras da Universidade Federal da Paraíba. Mestra e graduada pela mesma instituição. ORCID: https://orcid.org/0000-0002-5379-5535 / lucianapriscilasc@gmail.com

ii Doutora em Letras (UFRGS). Professora adjunta da UFPB, Campus I, membro permanente do PPGL. Orientadora de mestrado. Autora de, entre outras obras, $O$ trágico e o demoníaco em $O$ Evangelho segundo Jesus Cristo, de Saramago (EDUFPB, 2016). Líder do Grupo de Pesquisa em Estudos de Literatura e Sociedade Contemporânea. Pesquisadora do CesA (Centro de Estudos sobre África, Ásia e América Latina). ORCID: http://orcid.org/0000-0003-3137-2328/vanessariambau@gmail.com
} 
Ribeiro, Lívia Natália and Luana Genot use Instagram as a tool to expand their reflections and important social debates. In addition to so many other social contributions outside the virtual universe, the three writers cited here act in their Instagram posts as activists for women and the black body, and foster discussions that spread across the online world reaching real world, analyzing facts, speeches and behaviors from an anti-racist viewpoint, calling the entire society to reflect, contribute and participate effectively in the fight against racism.

Keywords: Anti-racism; Social networks; Instagram.

\section{PARA COMEÇAR ...}

Não pretendemos aqui fazer uma contextualização histórica do movimento feminista e das muitas discussões em torno dos feminismos. Compreendemos que esse conhecimento é primordial a todos, pois é por meio do conhecimento dessas vozes antes encarceradas, dos protagonismos dessas mulheres, que podemos paulatinamente progredir para uma sociedade mais justa, menos machista, hegemônica e mais humana. Destarte, ao longo da história, muitas pesquisadoras, escritoras, militantes, mulheres ativas na luta contra o patriarcado e os inúmeros abusos que as mulheres - negras, amarelas, brancas, pobres, cis, trans, em todas as suas pluralidades - escreveram e ainda escrevem sobre os silenciamentos, lutas, conquistas e sobre o ato de resistência que é ser mulher.

Contudo, aqui buscamos analisar o cenário atual, a partir dos posicionamentos das ativistas negras no ciberespaço do Instagram quando falam sobre o antirracismo, circunstância intensificada no contexto de pandemia da covid-19, em 2020. Para isso, falaremos brevemente sobre o surgimento do movimento negro feminista, pautado também na ideia antirracista, a fim de entendermos como ele vem atuando no Brasil na era do Instagram, com o objetivo de analisar como as ativistas abordam o antirracismo, como se posicionam, se articulam e utilizam o ciberespaço como estratégia de ativismo, potencializando a expansão e a abrangência de seus discursos.

Consideramos que a rede social analisada tem exercido papel de destaque na divulgação dos debates das mulheres negras, bem como na recepção instantânea por parte de diferentes públicos, causada pela facilidade de circulação e pela interação 
proporcionada pela Internet, em especial quando acessada de smartphones. Desse modo, a partir dos conceitos de ciberespaço e ciberativismo, falaremos sobre a expansão da web, o uso dos smartphones como aparelho que possibilita maior acessibilidade ao mundo virtual e a interação dos movimentos negros a partir das redes sociais, possibilitando autonomia às vozes antes silenciadas, bem como compartilhamento e visibilidade. Destacaremos, também, o aumento do engajamento dos protestos antirracistas no ciberespaço do Instagram, ocasionado por fatores primordiais: a pandemia de covid-19, que colocou o mundo em isolamento; e os polêmicos casos de racismo e violência policial contra negros a âmbito mundial.

Por fim, apresentaremos três ativistas negras, atuantes na sociedade e no Instagram, que trataram da pauta antirracista no contexto da pandemia e das manifestações impulsionadas por episódios ocorridos de violência racial. São elas: Djamila Ribeiro, Lívia Natália e Luana Génot. Verificaremos seus discursos, por postagens feitas por elas em maio, junho e julho de 2020, período em que as discussões contra o racismo explodiram nas redes sociais. As publicações escolhidas para a nossa análise são direcionadas, principalmente, a como e por que ser antirracista. Este foco é necessário para a compreensão de que a ideia presente no termo em questão já existia antes mesmo das separações dos movimentos feministas; inclusive o fato de a maior parte das mulheres brancas não agirem com tal prática foi primordial para que as mulheres negras sentissem a necessidade de caminharem "sozinhas" contra a opressão interseccional que as atingiam. No entanto, veremos que, na atualidade, o uso do termo ganhou notoriedade, e a exigência das ativistas negras pela prática antirracista por parte das pessoas privilegiadas ${ }^{1}$ passou a ser mais enfática, bem como compartilhada.

\section{A EMANCIPAÇÃO DO MOVIMENTO FEMINISTA NEGRO E A EXPANSÃO DO CIBERATIVISMO NO INSTAGRAM}

O movimento feminista permanece em constante reconstrução, seja por sua essência ligada à discussão sobre o gênero, seja pelas inúmeras divisões causadas pelos desencarceramentos de vozes que simbolizam as minorias oprimidas pelo sistema dominante. A pauta clássica feminista não favorece um grupo heterogêneo, ela diz respeito basicamente às mulheres brancas de classe social média ou alta. A tomada de 
consciência por parte das mulheres negras aconteceu quando estas mulheres se perceberam excluídas dos discursos reivindicatórios. Afinal, ao lutar pelos direitos das mulheres negras, o fator raça deve ser considerado, já que traz múltiplas experiências de opressão sofridas pelos corpos femininos negros.

Em E eu não sou uma mulher? Mulheres negras e feminismo (2014), Bell Hooks comenta sobre o famoso discurso de Sojourner Truth, além de fazer uma minuciosa análise sobre o surgimento do movimento feminista negro. O texto de Hooks enfatiza o posicionamento da mulher negra, contrariando muitas falas teóricas que insistem em colocá-la como ausente ou submissa durante um longo período da história. A autora prova a participação ativa destas mulheres em movimentos e atividades sociais, por meio de manifestos, escrita, trabalho, dentre outras atividades. No entanto, historicamente, seus posicionamentos e atos foram invisibilizados e suas falas, silenciadas. Pode-se dizer que o mesmo aconteceu dentro do movimento feminista.

Na década de 1980, quando publicou a primeira edição de seu livro, Hooks chamou a atenção para a linguagem escolhida na maioria dos textos de temáticas feministas, escritos por mulheres brancas: quando se referem aos homens, enfatizam tratar-se de homens brancos; quando se referem às mulheres, utilizam apenas o termo "mulher", claramente negando a existência da pluralidade contida no movimento, referindo-se apenas à mulher branca. Nestes mesmos textos, são feitas alusões às diferenças entre homens brancos e homens negros, e o lugar da mulher (branca) é colocado no mesmo patamar do homem negro, sem nenhuma referência à negra. A linguagem entrega o que está latente nos discursos: o movimento feminista clássico defende apenas a causa do sexismo branco, ignorando questões de raça, classes e outras minorias, além de excluir as causas das mulheres negras de suas pautas.

Apesar de os discursos comprovarem tal exclusão, as feministas brancas buscavam negar a omissão das causas negras e relutavam em reformular o pensamento do movimento. Consoante Hooks:

Porque as feministas tendem a evocar a imagem das mulheres como um grupo coletivo, as suas comparações entre "mulheres" e "negros" são aceites sem questões. Esta constante comparação sobre o dilema das "mulheres" e dos "negros" afasta a atenção do facto de que as mulheres negras são extremamente vitimizadas pelo racismo e sexismo - um facto que, se tivesse sido enfatizado, podia ter desconcentrado a atenção pública das queixas das feministas brancas de classe média e alta (HOOKS, 2015, p. 102). 
Também sobre tal omissão, em defesa de um "Feminismo afro-latinoamericano", Lélia Gonzalez (2020, p. 41) questiona o "esquecimento" da pauta racista perante o movimento feminista. A resposta que a teórica encontra sobre o assunto é obtida pelo termo "racismo por omissão", intitulado por cientistas sociais, ou seja, pautas antirracistas são esquecidas em prol da manutenção da visão eurocêntrica e neocolonialista.

Impulsionado pela resistência a suas colocações, o movimento feminista se dividiu, surgindo, então, o movimento feminista negro. Perante toda a insistência das correntes que defendiam a irmandade entre as mulheres, sem reconhecer a importância de se colocar em pauta, por meio desta união, as diferentes causas e de se considerar as mais distintas experiências e suas interseccionalidades, acreditamos que, inicialmente, foi de extrema importância a criação de um movimento de mulheres negras. $\mathrm{O}$ rompimento fez-se necessário, pois mesmo com a participação ativa na sociedade, elas continuavam silenciadas. Para Hooks:

\footnotetext{
No ensaio de Catherine Stimpson sobre a libertação das mulheres e dos direitos civis dos negros, no qual ela argumenta que "a libertação dos negros e a libertação das mulheres deve seguir em vias separadas", os direitos civis negros são associados aos homens negros e a libertação das mulheres às mulheres brancas. Quando ela escreve sobre o movimento das mulheres no século XIX, ela cita do trabalho dos homens negros líderes, ainda que as mulheres negras tenham sido mais ativas no movimento do que qualquer líder negro (2015, p. 103).
}

O movimento feminista negro é pautado pela intersecção das categorias opressoras. As violações sofridas pelas mulheres que compõem este ativismo não se restringem ao sexismo, muitas vezes estando intrinsicamente ligadas a raça, classe, orientação sexual e até a identidade de gênero. Cada condição pertencente a elas pode intensificar os obstáculos e as dores de suas experiências. Portanto, uma mulher branca de classe alta, vítima de abuso sexista, não está no mesmo contexto de opressão das negras, amarelas, ou até mesmo da branca pobre. Além disso, como bem explicita Sueli Carneiro em Enegrecer o Feminismo: a situação da mulher negra na América Latina a partir de uma perspectiva de gênero (2013), na história da luta por direitos das mulheres, enquanto as brancas lutavam por independência, vimos as negras serem obrigadas a tais "independências", enquanto as brancas lutavam por terem direito ao 
trabalho, as negras já trabalhavam e sustentavam suas casas sozinhas. Aliás, subempregos de babá ou doméstica geralmente eram executados em casas de pessoas brancas.

Quando falamos em direitos das mulheres, devemos pensar em todas e nos lembrarmos das especificidades de cada uma; quando colocamos todas em um mesmo lugar, consequentemente reivindicamos apenas os direitos das que ainda assim são mais privilegiadas: as brancas, de classe média/alta, heterossexuais e cisgênero. A partir do momento em que todas passam a lutar por condições iguais e não apenas as de interesse próprio, a luta torna-se sólida, livre de hierarquias dentro do próprio movimento. Negar a necessidade de se falar sobre o racismo sofrido pelas mulheres, justificando o ofuscamento de uma "causa maior", é perpetuar a denominação hegemônica entre as raças; é, ainda, acreditar que pessoas brancas têm prioridades. $\mathrm{O}$ discurso do não racismo é insuficiente, é necessário abraçar as causas antirracistas, e não só elas, mas as diversas que lutam contra a opressão do gênero. Trazendo a discussão para os países latino-americanos, Gonzalez (2020, p. 42) afirma que

[...] o feminismo latino-americano perde muito da sua força ao abstrair um dado da realidade que é de grande importância: o caráter multirracial e pluricultural das sociedades dessa região. Tratar, por exemplo, da divisão sexual do trabalho sem articulá-la com seu correspondente em nível racial é recair numa espécie de racionalismo universal abstrato, típico de um discurso masculinizado e branco. Falar da opressão da mulher latino-americana é falar de uma generalidade que oculta, enfatiza, que tira de cena a dura realidade de mulheres vivida por milhões de mulheres que pagam um preço muito caro pelo fato de não serem brancas.

Escrito há mais de trinta anos, o texto de Hooks continua atual. Dentro da falta de diálogo entre os grupos, a polarização ainda propicia animosidade entre as diversas vertentes do feminismo. Aqui consideramos que opressões - intensificadas ou não não se anulam, continuam fazendo parte de um sistema estrutural de dominação, que deve ser questionado e combatido insistentemente. Perpetuar uma divisão e não praticar a escuta, a empatia e o direito de fala de todos parece não ser o caminho mais consciente nas pautas ativistas. Bell Hooks é enfática em dizer que "todas as mulheres deviam experienciar afirmação e apoio em grupos racialmente misturados. O racismo é a barreira que impede a comunicação positiva e não é eliminado ou desafiado através da separação" (HOOK, 2014, p. 109). Para que possamos aprender a lutar por pautas que 
deveriam ser de todos, é preciso fomentar o diálogo no maior número de espaços possíveis, tocar e conscientizar pessoas de seus privilégios ou da ausência deles, a expansão do debate é fator fundamental para a ampliação do público defensor dos direitos das mulheres que se encontram na intersecção das discriminações.

Desse modo, os debates sobre os feminismos têm ganhado cada vez mais espaço, antes restrito aos movimentos e ao universo acadêmico, é notório sua presença em espaços sociais distintos, como escolas, comunidades religiosas e mídias da comunicação. Contudo, tal abertura foi possibilitada pelo avanço da tecnologia, principalmente pela Internet, principalmente pela rede móvel. O mundo virtual e globalizado já possibilita o acesso às informações e interações práticas há algum tempo; no entanto, tais possibilidades eram de uso exclusivo da classe média/alta.

Nos anos 2000, o boom dos blogs e sites pessoais foi fundamental para que as pessoas tivessem seus espaços de fala e pudessem divulgar suas ideias e posicionamentos de forma rápida para um grande número de internautas. Segundo Amaral, Recuero e Montardo, os blogs foram alavancados pelo surgimento das ferramentas de publicações, que facilitaram as postagens:

\begin{abstract}
Em 1999, a Pitas lançou a primeira ferramenta de manutenção de sites via web, seguida, no mesmo ano, pela Pyra, que lançou o Blogger. Esses sistemas proporcionaram uma maior facilidade na publicação e manutenção dos sites, que não mais exigiam o conhecimento da linguagem HTML e, por isso, passaram a ser rapidamente adotados e apropriados para os mais diversos usos. Além disso, a posterior agregação da ferramenta de comentários aos blogs também foi fundamental para a popularização do sistema (AMARAL et al., 2008, p. 28).
\end{abstract}

Além dos comentários, os chats hospedados em diversos sites funcionavam como espécies de comunidades formadas para conversar sobre assuntos preestabelecidos. A chegada do Facebook - no momento em que já se expandia a banda larga, que facilitava o acesso à Internet - também foi importante para as pessoas, por meio seus perfis, levantar debates importantes e organizar movimentos entre as comunidades virtuais, culminando em manifestações nas ruas. Era o tempo das lan houses, as pessoas sem computador ou acesso à Internet em casa iam àqueles espaços, em busca de pagar algumas horas de acesso à Internet quase diariamente. Mas, ainda assim, podemos considerar que o acesso aos debates gerados virtualmente era limitado pois, no Brasil, aquela não era a realidade da maior parte da população, sem grande 
poder aquisitivo e bastante influenciada pela mídia tradicional - televisão e rádio manipuladora do conteúdo destinado à grande massa.

No mesmo período em que o acesso ao mundo virtual se intensificava, o campo da telefonia também avançou. A evolução de celulares para smartphones, as variedades de preços e as condições de pagamento ampliaram o "público internauta", que presenciou os aparelhos ganharem uma gama de funções e, consequentemente, transformar-se em computadores que cabem nas palmas das mãos. Além disso, trazem, em suas tecnologias, o acesso a wi-fi e Internet móvel, permitindo o acesso ao mundo digital onde quer que estejamos. Cada vez mais conectados, celulares e redes sociais (como Facebook e Instagram) passaram a ser uma espécie de extensão do corpo das pessoas - não só dos brasileiros. As redes sociais são espaços virtuais de comunicação nas quais os participantes criam perfis pessoais para produção de conteúdos e compartilhamento de conteúdos de outras pessoas; assim, tais informações publicadas podem ser vistas e cruzadas entre os usuários, gerando produção, consumo e interação entre os participantes (RECUERO; BASTOS; ZAGO, 2015, p. 26).

Diante deste cenário, as oportunidades se expandiram: pessoas que antes não tinham espaços de fala, emudecidas pelas grandes mídias ou movimentos hegemônicos, sem acesso a ambientes fomentadores de uma discussão em prol da massa, encontraram uma ferramenta de não silenciamento, um espaço próprio para a fomentação de debates de interesses de muitas outras pessoas às quais tais discussões não eram possibilitadas.

A partir desta expansão tecnológica, podemos dizer que sociedades foram construídas virtualmente. Assim, a definição de social saiu do âmbito mais concreto e ganhou forma no meio digital, pois é neste cenário em que as interações, as ações, os debates e as organizações de pessoas vêm se intensificando. Pelas redes sociais, a noção de vida privada parece estar ganhando outro significando; atrás das telas dos smartphones, os indivíduos informam suas rotinas, seus passos, seus interesses e opiniões. Protegidos atrás de um aparelho telefônico, os internautas se sentem livres para manifestar suas opiniões e até mesmo despejar seus discursos de ódio, julgamentos que, presencialmente, muitas vezes são comedidos, mas que no mundo virtual ganham força com apenas um clique. Por isso, também, enxergamos o aumento da militância nas redes que lutam contra os ataques virtuais e presenciais. Assim, a convivência no meio virtual está sendo construída e ressignificada diariamente, possibilitando a 
percepção da formação de uma verdadeira noção de cultura. Segundo Lemos (2005, p. 1-2), a "cibercultura representa a cultura contemporânea sendo consequência direta da evolução da cultura técnica moderna", além disso, o termo também pode indicar a "socialidade na técnica e a técnica na socialidade" (LEMOS, 1997, p. 4).

Em todo âmbito social, seja no real ou no ciberespaço, faz-se crucial a participação pela democracia. A luta encabeçada pelas participantes do feminismo negro ganhou uma nova dimensão nos últimos anos. Aproveitar o ciberespaço e compreender que, atualmente, ele é o caminho mais rápido para ações se reverberarem nas ruas foi o pensamento estratégico destas ativistas. Segundo Resende et al. (2015), utilizar as vantagens do ciberespaço é uma das estratégias dos novos ativismos, o que, na prática, podemos chamar de ciberativismo. Para o autor, esta é

\footnotetext{
uma forma de ativismo através da internet, ainda que seja necessária a existência do ativismo real. Utilizado, principalmente, por grupos politicamente ativos, essa forma de ativismo é realizada com a intenção de divulgar e abrir espaços para determinadas causas e possíveis discussões sobre os assuntos. Além disso, aqueles que utilizam dessa prática acreditam que essa seja uma alternativa aos meios de comunicação em massa tradicional (RESENDE et al., 2015, p. 3).
}

Assim, as feministas negras, com o ciberatisvismo e no ciberespaço, têm maiores oportunidades de articular as reivindicações políticas, pois a Internet (principalmente a móvel) facilita a interação entre militantes de todos os lugares do mundo, permitindo a criação e o debate das pautas dos movimentos e da inserção das discussões nas agendas políticas, intervindo pelo meio virtual, impactando diretamente no mundo real. Confirma-se o pensamento de Lemos e Lévy, quando afirmam que o ““sentido’ da tecnologia contemporânea não se refere a sua dimensão material, mas sim ao seu poder de produzir sentido, de fazer sociedade” (LEMOS; LEVI, 2010, p. 30).

O Instagram é uma rede social que tem funcionado como campo de atuação de muitas ativistas da negritude. $\mathrm{O}$ aplicativo possibilita o compartilhamento de imagens, textos, vídeos gravados e ao vivo (as chamadas lives). Por seu grande número de usuários e engajamento, a rede tem sido palco para grandes debates e discussões militantes. $\mathrm{O}$ crescimento do ativismo na rede social tem se tornado parte essencial dos usuários mais famosos, estes - denominados "influenciadores digitais" -, quando não emitem suas opiniões sobre assuntos relevantes do momento, são cobrados a se 
posicionarem. Percebe-se, então, que no ciberespaço, não basta apenas influenciar milhões de seguidores, mas também há de se mostrar proatividade nas agendas políticas. Para além disso, a ferramenta trouxe, à Internet, personalidades das mídias tradicionais, figuras que pouco se expressavam, por terem vínculos trabalhistas com empresas midiáticas importantes, uma vez que, no universo do Instagram, a omissão quanto a episódios importantes para a cultura é pouco aceitável, assim, é possível vermos mais pessoas livres (ou pressionadas) a assumirem uma posição política e social. Mais importante do que trazer personalidades da mídia tradicional aos debates, a rede propiciou o aumento da visibilidade das minorias, como os anônimos de origem humilde que ganharam destaque e conseguiram fazer fortuna a partir do grande engajamento conquistado na plataforma.

Outro ponto fundamental a se destacar é o evidente crescimento participativo das mulheres negras no Instagram. Elas marcam presença em todos os assuntos que permeiam o aplicativo de celular e web, falam de moda, arte, tecnologia, literatura, política, cultura, humor, entre outros temas. Além disso, muitas aproveitam o espaço livre de silenciamento para expor a defesa de suas causas, como ressignificação e empoderamento do corpo feminino negro, lugar de fala da mulher negra, literatura de autoria negra feminina, racismo estrutural e antirracismo. Elas trazem a representatividade para muitas outras mulheres, que não conseguiam se enxergar nos modelos impostos pelas mídias tradicionais. A sociedade contemporânea passa boa parte de seu tempo diário conectada às redes via celular, assim a televisão e o rádio perderam destaque, sendo obrigados a tomarem proveito dos sucessos obtidos no meio virtual. As personalidades mais conhecidas e requeridas já não estão mais apenas na televisão, mas em redes como Youtube e Instagram; já não são mais apenas as que pertencem ao padrão hegemônico, mas também aquelas que representam as diversidades.

Portanto, progressivamente, as mídias clássicas passaram a inserir estas novas personalidades em suas programações, tanto em programas de entretenimento, jornalísticos como em campanhas publicitárias. Consideramos que tal inclusão não ocorreu porque alcançamos uma sociedade menos machista, menos racista e mais humanizante. Este processo se deu pela autonomia de participação social obtida pelas redes sociais e, principalmente, pelo Instagram. Veremos que estas mulheres negras 
demarcam seus lugares no ciberespaço, agem com protagonismo e conquistam um público cada vez mais engajado, diverso e consciente das agendas políticas. Perceberemos também que não só as mídias de comunicação e entretenimento tradicionais são obrigadas a rever seus discursos e agentes, mas notamos que mesmo o mercado de consumo, como a indústria de cosméticos, passa a criar produtos para o público feminino negro e a abrir mais espaços de representatividade entre as embaixadoras que compõem as marcas comerciais.

\section{A PAUTA ANTIRRACISTA NO InStagram DURANTE A PANDEMIA}

O ano de 2020 expandiu ainda mais o uso das tecnologias devido à pandemia de covid-19. Na falta de vacina, o isolamento se fez necessário a todos os países como tentativa de conter a disseminação do vírus e a falta de leitos nos hospitais. Trancadas em casas com saídas autorizadas apenas para fins essenciais, as pessoas viram o ciberespaço como o lugar possível de maior sociabilização. Assim, os períodos de quarentena têm reafirmado o papel do âmbito virtual na formação de ativismos e significados coletivos.

Para além da pandemia, aconteceram episódios de violência racial, revoltando a população mundial, que mostrava sua indignação no único espaço possível: a Internet. Entre os episódios mais marcantes, o caso do americano George Floyd foi o estopim para as manifestações antirracistas. Em 25 de maio de 2020, a divulgação de um vídeo nas redes sociais causou uma onda de indignação. Nele era possível observar um policial branco ajoelhado sobre o pescoço de Floyd, um homem negro de 40 anos, que gritava repetidamente: "não consigo respirar". Logo depois a vítima imóvel é filmada sendo levada em uma ambulância. Tarde demais. Um episódio parecido aconteceu com Eric Garner, em 2014. Também ele repetiu por 14 vezes a frase: "não consigo respirar!". O assassinato de Floyd foi associado ao de Garner por suas semelhanças. Por cansaço da violência policial e da supremacia branca, diversas manifestações eclodiram primeiramente no mundo virtual, depois os manifestantes foram às ruas (mesmo contra a indicação dos governantes e da Organização Mundial de Saúde), com a frase-símbolo das manifestações: "Black lives matter" ou, em português, "Vidas negras importam". 
Antes de ganhar repercussão nas ruas em 2020, o grito pelas vidas negras se disseminou na Internet, mais precisamente no Twitter, em 2013, quando três mulheres negras levantaram na rede a hashtag (\#blacklivesmatter) e, juntas, formaram o movimento Black Lives Matter (BLM). Segundo o site do movimento, BLM é uma "intervenção política e ideológica em um mundo onde vidas negras são sistemática e intencionalmente desaparecidas". Além disso, a frase "é uma afirmação da humanidade das pessoas negras, da nossa contribuição para a sociedade, da nossa resiliência em face dessa opressão fatal". A contribuição das ativistas negras Alicia Garza, Patrisse KhanCullors e Opal Tometi ganhou destaque mundial em maio de 2020, quando o nome do movimento foi utilizado como grito de protesto em diversos países, em que as pessoas não podiam silenciar a morte de Floyd e de mais nenhuma vida negra.

Apesar de boa parte da população ir às ruas usando máscaras como medida de proteção contra o coronavírus, muitos cidadãos ainda respeitavam o isolamento. No Brasil não foi diferente, as pessoas também se manifestaram nas ruas, porém predominaram as reivindicações no Instagram, principalmente após a morte do jovem João Pedro, assassinado em uma operação policial no Rio de Janeiro. O isolamento em razão da pandemia não impediu que os policiais invadissem a casa do adolescente e o atingissem com um tiro de fuzil na barriga. Outro caso que também repercutiu muito no ciberespaço, e consequentemente nas grandes mídias, foi a morte do menino Miguel Otávio Santana, de cinco anos. A mãe do menino, empregada doméstica, precisou levar os cachorros dos patrões para passear, deixando o filho sob supervisão de sua patroa. Miguel, procurando sua mãe, foi até o elevador com permissão da pessoa que cuidava dele, desceu em um andar qualquer, escalou uma mureta, caiu do prédio e faleceu. Cabe ainda recordar o triste episódio de João Alberto Silveira Freitas, de 40 anos, que foi covardemente espancado até à morte por seguranças do supermercado Carrefour, em Porto Alegre, depois de ter feito algum gesto interpretado como ofensivo a uma funcionária do estabelecimento. Um homem negro que fazia compras com sua esposa e foi assassinado sem chance de defesa em plena luz do dia.

A fim de analisarmos como as influenciadoras negras utilizaram a rede social em seus ativismos no contexto da pandemia e do aumento das reivindicações antirracistas devido aos casos polêmicos mencionados, selecionamos três mulheres com diferentes números de seguidores (público), mas que se destacam no ciberativismo no Instagram e 
em outros âmbitos. Destacaremos aqui as ações de Djamila Ribeiro, Luana Génot e Lívia Natália. Essas ativistas viram nas redes sociais (principalmente no Instagram) a ferramenta capaz de subsidiar as manifestações que buscavam para protestar sobre a violência sofrida pelas vidas negras e ensinar sobre o antirracismo, bem como falar da importância de as pessoas agirem e se posicionarem como antirracistas.

A filósofa e escritora Djamila Ribeiro tem atualmente mais de 1 milhão de seguidores em seu perfil do Instagram e já fez mais de 2.500 publicações. Além de se posicionar na rede social, a ativista é colunista do jornal Folha de S. Paulo e da revista Elle Brasil. Também é autora de livros teóricos que abordam a questão feminista e racial, principalmente em nosso país, entre eles a coleção "Feminismos Plurais" e o Pequeno Manual Antirracista, de 2019. Ribeiro também é detentora de prêmios nacionais e internacionais por sua atuação feminista e antirracista e, em 2019, foi eleita pela BBC uma das 100 mulheres mais influentes de todo o mundo. Em seu Instagram, é possível encontrar postagens sobre racismo, feminismo e empoderamento feminino, além de ser possível acompanhar um pouco da sua vida privada, um ponto comum entre muitas personalidades da rede social, o que aproxima o público, que se vê no cotidiano dessas influenciadoras.

No ano de 2020, durante a pandemia e após as polêmicas violências contra as vidas negras, a filósofa focou suas publicações na temática antirracista, e passou a fazer publicações didáticas sobre o tema no perfil do ator precocemente falecido Paulo Gustavo (1978-2021), o que levou outras personalidades brancas a cederem seus perfis como estratégia de ampliação do discurso das feministas negras na rede social, atingindo um público maior e variado. Segundo Djamila Ribeiro, em postagem no Instagram no dia 3 de junho de 2020:

[...] o querido@paulogustavo31, entendendo lugar de fala como uma postura ética, numa atitude, arrisco dizer, inédita nesse país, convidou-me para ocupar sua página, com mais de 13 milhões de seguidores, pelo mês de junho. Lá, compartilharei com vocês vídeos sobre relações raciais, dialogando com quem vem se conscientizando, bem como trazendo para reflexão parte de um público que ainda não é acostumado com o tema. Nos vídeos, apresentarei autoras e autores que vêm falando sobre esses temas, bem como iniciativas importantes. Só tenho a agradecer a Paulo Gustavo por esse posicionamento consciente. Lugar de fala é isso: como eu, do meu lugar social, posso impactar para a equidade do grupo em condições sociais desfavorecidas? (RIBEIRO, 2020). 
Assim, além de continuar postando em seu perfil, a escritora compartilhou muitas informações no perfil do ator, gerando grande engajamento e repercussão, sendo esta ação em conjunto divulgada em outras mídias. Na primeira publicação, Djamila se apresentou ao público de 13 milhões de internautas que seguiam o dono do perfil e explicou que a ação funcionaria como aulas, em que ela abordaria assuntos importantes para a pauta antirracista, como relações raciais, lugar de fala, racismo estrutural e assuntos referentes à sociedade. Ao propor abordar tais assuntos, ela trouxe para o universo do Instagram, e, consequentemente, outros espaços conceitos intrinsicamente ligados à academia e aos movimentos negros, que nos permitem entender a complexidade em que se estruturam os modos de dominação por parte das classes hegemônicas. Em outra postagem no perfil "emprestado", Ribeiro introduziu o tema do antirracismo:

\begin{abstract}
A mudança da sociedade não se faz apenas com denúncias ou repúdio moral do racismo. Ou seja, independe se a pessoa é legal, simpática ou gentil com pessoas negras. Depende, antes de tudo, da tomada de posturas e da adoção de práticas antirracistas [...]. Não basta não ser racista. É preciso ser antirracista, já nos ensinou Angela Davis. [...]. No nosso próximo encontro, aprofundaremos um pouco mais no tema. Até lá, deixo a pergunta: quais ações vocês estão tomando ou pretendem fazer em prol da luta antirracista?
\end{abstract}

No contexto em que as publicações eram feitas, como já relatamos anteriormente, os usuários do Instagram estavam em polvorosa, tecendo considerações, levantando hashtags contra o racismo e apoiando as vidas negras e os movimentos de negritude. Aproveitando o espaço cedido e seu lugar de fala, a ativista tocou na ferida de muitos brasileiros que acreditavam fazer diferença ao se intitularem não racistas ou ao compartilharem uma imagem com a frase "Vidas negras importam". Afinal, o que é ser antirracista? Será simplesmente ser gentil com pessoas negras ou compartilhar “\#blacklivesmatter"? Na publicação seguinte, intitulada de "O antirracismo na prática”, com mais de 215 mil visualizações e mais de 800 comentários, Ribeiro postou um vídeo em que procura de forma didática explicar como agir diante do racismo de forma prática cotidianamente:

Acredito que esses nossos encontros aqui no espaço do Paulo Gustavo estão servindo para termos a dimensão do desafio, uma vez que se trata de um contexto tão enraizado em nossa cultura. No vídeo de hoje, falaremos um pouco sobre antirracismo na prática. Esse 
vídeo procura orientar uma introdução no assunto, visto que a ação antirracista é diária, visa o compromisso e, evidentemente, varia conforme a realidade de cada indivíduo. Vamos investigar juntos como podemos impactar na realidade de grupos vulnerabilizados socialmente. Quando temos a consciência de que o racismo é parte da estrutura social, por mais que calarse diante do racismo não faça do indivíduo um culpado ou responsável, certamente o silêncio torna-o responsável pela manutenção do racismo. Por isso, para além da consciência, devemos transformá-la em ação concreta. Mas como fazer isso? Nesse vídeo, vamos descobrir alguns caminhos. Sejamos parte da transformação! (RIBEIRO, 2020).

$\mathrm{Na}$ introdução do vídeo, a escritora retoma alguns ensinamentos passados nas publicações anteriores e cita nomes importantes na história dos movimentos negros, como Kabengele Munanga que, ao dizer que não existe racismo melhor ou pior, fala também da importância de se questionar o mito da democracia racial e a romantização da escravidão difundida por Gilberto Freyre. Ao citar nomes e referências, a ativista leva a conhecimento do público outros pesquisadores da negritude, permitindo que os usuários interessados tenham facilidade na busca por mais informações. Como sugestões de práticas antirracistas, ela enumera: fazer leituras e obter informações sobre o racismo, questionar e não naturalizar a ausência das pessoas negras nos espaços ou o lugar de subalternidade em que elas se encontram, conhecer as realidades das pessoas negras, bem como as origens sociais das desigualdades. Segundo Djamila, na publicação intitulada "A prática antirracista é urgente e se dá nas atitudes mais cotidianas", as pesquisas mostram que a população negra brasileira se encontra na base da pirâmide; a ascensão não ocorre porque as oportunidades não são iguais, para ela, também "não se trata de um debate de capacidade. Capacidade sabemos que temos. São as oportunidades que não são iguais".

Nas publicações seguintes, Ribeiro comenta sobre a importância de as pessoas compreenderem que não precisa ser negro para falar sobre o racismo, pois pessoas brancas podem e, segundo a autora, devem debater o racismo. Consideramos que assim Ribeiro abre espaço para uma discussão muito polêmica na pauta antirracista. Com a expansão do termo "lugar de fala", muitas pessoas têm confundido o sentido do termo e muitas acreditam que, sim, só os negros podem falar sobre o racismo. No entanto, na publicação de 16 de junho de 2020, ela alerta:

Muito tem se falado sobre o que é lugar de fala, um conceito claramente mal compreendido sobretudo por aqueles que insistem em criticá-lo. A confusão sobre o tema se dá essencialmente porque é correlacionado com 
representação, afinal, você precisa ser negro para falar contra o racismo? Lugar de fala é um conceito que vai muito além do ato de emitir palavras, ele diz respeito à própria existência, o poder existir; para isso, mais do que falar é necessário educação de base e políticas públicas eficientes, que sejam capazes de quebrar e desconstruir a voz única, masculina, branca, eurocêntrica e cristã que controla todas as narrativas. O homem branco se enxerga universal, como se fosse uma metáfora do poder e, via de regra, não compreende que fala a partir de um lugar e de um grupo. Não enxerga que sua fala gera impactos diretos em outros lugares sociais e que todo privilégio que usufrui foi construído com base na opressão de outros grupos. Através dos debates entre militantes e polêmicas constantes nas redes sociais, "LUGAR DE FALA" se tornou um dos conceitos mais importantes da atualidade. Com as políticas de identidade se fortalecendo e ocupando cada vez mais espaços nas agendas políticas e a internet democratizando em massa a comunicação, os grupos oprimidos conquistam cada vez mais força ao falarem ativamente sobre suas condições e realidades, realocando constantemente as geografias da razão. Lugar de fala é, acima de tudo, uma discussão de poder (RIBEIRO, 2020).

Em todas as publicações de Djamila, os comentários e as curtidas (ferramentas do Instagram) mostram o nível de alcance das discussões. Milhares de pessoas foram alcançadas e geraram debates na rede social; dentre os comentários é possível perceber que não apenas ativistas e militantes interagiram, mas também leigos no assunto que queriam entender sobre a discussão e até mesmo os negacionistas se manifestaram, colocando o racismo como uma invenção social. Enquanto a filósofa utilizava o Instagram de uma personalidade branca com o propósito de alcançar um número significativo de pessoas, outras ativistas continuaram fazendo ações em seus perfis particulares. Como dito anteriormente, Djamila e Paulo Gustavo estimularam outras personalidades a trocarem os perfis na rede social para fomentar a discussão antirracista, no entanto, nem todas as ativistas negras concordaram com esta estratégia. Uma delas foi a poeta Lívia Natália.

Além de poeta, Lívia é professora do Instituto de Letras da Universidade da Federal da Bahia (ILUFBA), Doutora em Teoria da Literatura pela Universidade Federal da Bahia (UFBA). Ela também é autora de ensaios teóricos sobre feminismos e relações raciais e literatura e atua no âmbito da escrita literária com produções autorais, entre os quais destacamos Correntezas e outros estudos marinhos, publicado em 2015, e Dia bonito pra chover, publicado em 2017. No ano 2020, a poeta também se manteve engajada no ativismo no Instagram. Em seu perfil, com mais de 7 mil seguidores, ela aborda temáticas antirracistas, divulga campanhas e eventos em torno do tema, fala sobre experiências das mulheres negras, além de interagir com o público em lives e 
publicações sobre literatura e cultura negra. Lívia Natália está à frente do projeto "Letras Negras", um programa em que ela convida personalidades negras para conversarem sobre literatura e pautas da negritude. Com esta iniciativa, a autora leva ao público o conhecimento de nomes literários importantes e ainda poucos conhecidos pelos brasileiros, permitindo a divulgação de personalidades da literatura de autoria feminina negra, principalmente.

Em uma publicação sobre a prática antirracista, no dia 17 de junho de 2020, Lívia Natália criticou a dinâmica de troca de perfis para falar sobre negritude. A imagem postada pela poeta para ilustrar sua publicação foi planejada para chamar atenção; almejava fazer seu público parar e ler o que ela precisava falar. A foto tem fundo preto com letras brancas e grandes e traz a seguinte afirmação: "Esta história de ocupar o perfil de branco-modinha-pretensamente antirracista é massa", em seguida, em destaque vermelho, ela questiona: "Mas é massa para quem?". Nas imagens seguintes, a ativista segue fazendo questionamentos e apresentando seu ponto de vista. Primeiro, ela questiona o lugar cômodo dos influenciadores brancos, que saíram de cena e não se envolveram no debate, apenas "emprestaram" seus perfis para que os influenciadores e influenciadoras negras militassem sozinhos. Lívia explica que, ao fazer isso, essas figuras públicas não mostram interesse real, não estudam, não perguntam e não se colocam no lugar de aprendizado, mas impõem esse lugar para seus seguidores.

Outro ponto importante no contra-argumento da escritora se dá quando ela reconhece a importância da audiência emprestada (milhões de seguidores) e, consequentemente, o espaço na mídia, mas alerta sobre o fato de colocar um preto ou uma preta para falar sem interação real com os donos dos perfis, o que, em sua concepção, pode gerar a interpretação e o reforço no pensamento de que o racismo é um problema apenas dos negros e das negras. Consideramos pertinente a visão de Lívia Natália, afinal, vimos no início deste ensaio, durante as falas de Bell Hooks, que a maior dificuldade das mulheres negras dentro do movimento feminista era fazer as outras mulheres entenderem que o racismo era um problema de todos, e não só das oprimidas.

$\mathrm{Na}$ mesma publicação, Lívia mostra como vê o resultado desta campanha: a branquitude $^{2}$ brasileira diz fazer sua parte, ao emprestar o perfil no Instagram, mas não se envolve diretamente; sai como herói ou heroína antirracista; e nada muda, pois o negro ou a negra continuam lutando sozinhos. A análise da pesquisadora sobre o 
cenário do ciberativismo no Instagram em 2020 lembra que muitas vezes a opressão às minorias não se dá apenas por agressões, mas pode acontecer também por omissões. Quando, no início do movimento feminista americano, as mulheres brancas diziam que todas eram iguais e deveriam lutar pelos mesmos direitos, elas oprimiam por omissão as mulheres negras que falavam sozinhas e não viam iniciativas voltadas para elas dentro do movimento em que estavam; contudo, apesar da omissão, as mulheres brancas se aproveitavam das negras no movimento para se afirmarem antirracistas. Não podemos generalizar e dizer que todos os influenciadores brancos têm interesses e quiseram se aproveitar da agenda política dos movimentos contra o racismo para manter a opressão e, ao mesmo tempo, ganhar mais visibilidade. No entanto, dado o histórico do racismo estrutural brasileiro, não podemos ignorar essa possibilidade. Uma boa forma de encontrar quem simplesmente não aderiu de modo real ao discurso antirracista é analisar os perfis do instagramers que participaram do ápice do movimento no ciberespaço: quem continua em prol da pauta antirracista e quem continuou com a rotina de publicações e nem fala mais sobre racismo? A pesquisadora deixa clara a sua intenção provocadora. Segue o post da escritora:

\footnotetext{
O que eu penso sobre ocupar perfil de brancx-modinha pra ele se passar por antirracista? Dos pretos, eu não acho nada, jamais cairia nesta de fogo amigo. Cada um constrói sua militância como acha certo, e estamos juntxs. Este recado não é para minhas e meus irmãs e irmãos negras e negros. É para a branquitude confortavelmente acomodada no seu lugar. Saiba que sair e deixar uma pessoa negra lá, fazendo um trabalho que deveria ser compartilhado com você, é racismo. Se você não interage, não estuda, não pergunta, não comenta com suas palavras e mostra a sua cara branca pra se pensar, isso, (choque!) não é ser antirracista. É ainda dizer que racismo é problema de pretxs (NATÁLIA, 2020).
}

Luana Génot é outra ativista negra que provocou a discussão sobre o racismo e conscientizou os usuários do Instagram para a importância da luta antirracista. Ela é diretora-executiva do Instituto de Identidades do Brasil, o ID_BR, uma organização sem fins lucrativos, pioneira no Brasil e comprometida com a aceleração da promoção da igualdade racial. Também atua como colunista no jornal "O Globo" e é autora do livro Sim à Igualdade Racial (2019). Em seu perfil, é possível encontrar um destaque (ferramenta da rede que coloca em destaque as publicações escolhidas pelo dono ou dona do perfil) apenas sobre o antirracismo. O destaque intitulado "Antirracismo" compõe uma série textual em que Génot explica o conceito e as ações práticas. 
Na primeira publicação datada em 19 de junho de 2020 (mês em que se destacaram as campanhas sobre o antirracismo), intitulada por "Antirracismo para além das hashtags", a ativista chama a atenção de empresas que publicaram imagens contra o racismo e utilizaram as hashtags antirracistas. Luana fala sobre a importância de essas instituições começarem a agir na prática como antirracistas, e não apenas se colocarem como tal, afinal, postar foto e hashtag em solidariedade ao movimento não é uma atitude concreta:

\begin{abstract}
Acreditamos que a promoção da igualdade racial e luta antirracista vai para além das hashtags. [...]. Não precisamos de mais pessoas negras morrendo para tomar atitudes sólidas em relação a pauta antirracista. Nos EUA diversas marcas anunciaram milhões para direcionar ao combate ao racismo e fortalecimento da comunidade negra. Aqui no Brasil ainda nada. Vamos continuar acompanhando e cobrando na esperança de responderem (GÉNOT, 2021).
\end{abstract}

Ao cobrar das empresas, a ativista ensina a seu público sobre a importância das concretas ações cotidianas antirracistas e o estimula a sempre questionar as verdadeiras intenções das pessoas e empresas que abraçam a causa, assim como alertou Lívia Natália. Em outra publicação, Luana entende que a prática antirracista não pode estar só atrelada aos cidadãos comuns, mas também às pessoas que têm poder $\mathrm{e}$ responsabilidade social e econômica. A ativista mostra a importância de as grandes empresas investirem na igualdade racial, saindo da apatia das hashtags e sendo mais empáticas com reais oportunidades:

Receio? Lugar de fala? Há muitas lideranças que me procuram e a palavra que mais ouço é receio e o fato de não terem lugar de fala sobre a temática antirracista. Meu recado para CEOs e lideranças de empresas nacionais e multinacionais no Brasil é: Não tenham medo ou fiquem inertes ao chamado da pauta antirracista. Transformem sua apatia em empatia. Esta luta é de todos e todas nós. Não investir na pauta agora coloca em xeque o desenvolvimento de sua empresa. A conta sempre chega. Continuo convidando você a pensar e espalhar esta reflexão. Marque as empresas que você gostaria que tomassem medidas efetivas pela igualdade racial (GÉNOT, 2021).

Nota-se que uma das estratégias de Génot é utilizar uma linguagem imperativa, marcada pela força no chamado, clamando posicionamentos e ações transformadoras. Assim como Djamila Ribeiro e Lívia Natália, ela chama a branquitude e os privilegiados para lutarem junto, compreendendo seu lugar de fala, e agindo contra a 
perpetuação do racismo institucionalizado no país. O chamado de Luana Génot, quase em clemência, tem uma razão: para ela, nós “[...] precisamos ser intencionais em relação à pauta antirracista e não achar que ela já está sendo endereçada quando tratamos de problemas sociais e outros afins que são tão importantes". Ou seja, os protestos e a discussão na Internet e nas redes sociais são importantes, compreender o antirracismo também, mas não adianta ficar presos ao teórico, ao conhecimento, é preciso agir. E todos precisam agir, não apenas as pessoas negras. Outro ponto importante a se destacar é a seletividade empregada por muitos que se dizem antirracistas: Luana chama atenção para as posturas das pessoas que se comoveram com a morte de George Floyd, mas ignoram a morte de negros brasileiros, mais uma vez mostrando a seletividade do ativismo no Brasil.

\begin{abstract}
Há um mês e meio as redes sociais foram tomadas por quadradinhos pretos em adesão ao \#BlackoutTuesday e \#BlackLivesMatter depois da morte de George Floyd, nos Estados Unidos. Empresas e pessoas se pronunciaram, comovidas, contra o racismo que atinge a população negra que, nos EUA, representam 13\% do todo. Há alguns dias, uma senhora negra de 51 anos foi agredida, arrastada pelo chão e pisada por um policial em São Paulo, no Brasil. Não houve a mesma mobilização virtual a favor da vida desta mulher. As redes sociais não foram tomadas por \#blackouttuesday, quadradinhos pretos e \#VidasNegrasImportam. Nossa comoção é seletiva. Não é incomum acharem que o racismo existe nos EUA e que aqui é mais brando. $\mathrm{O}$ antirracismo é prática diária e não deve ser seletivo. Não podemos achar normal ser tocados apenas pelas violências internacionais, enquanto outras tantas acontecem aqui no Brasil, onde somos $56 \%$ da população e são normalizadas. Antirracismo é empenhar esforços e também recursos financeiros diretamente em projetos que ampliem as oportunidades para a população negra no mercado de trabalho e no combate ao genocídio negro e indígena. [...]. Se só o racismo internacional te comove, não é antirracismo, é seletividade (GÉNOT, 2021).
\end{abstract}

Assim, a diretora executiva do ID_BR reafirma a importância de as práticas e ações sociais serem sempre questionadas e revistas quando se trata de situações que envolvem as pessoas negras, o racismo e o antirracismo.

\title{
CONSIDERAÇÕES FINAIS
}

Ao pensarmos que uma questão foi aprendida, refletida e transformada, continuemos analisando nossos pensamentos e atitudes e procuremos as armadilhas do racismo estrutural neles. Como vimos, nos ativismos de Djamila Ribeiro, Lívia Natália 
e Luna Génot, não basta a alcunha de antirracista sem ações concretas. Ser antirracista exige estudo, aprendizado, reconhecimento dos privilégios, respeito aos lugares de fala, empatia, mudanças nas atitudes cotidianas, oportunidades e igualdade nos espaços sociais, igualdade nas lutas dentro do próprio movimento negro, bem como reconhecimento das pluralidades e igualdade de vozes. No entanto, desta vez não falamos de vozes que foram silenciadas, pois vimos que o espaço da Internet deu autonomia à voz dessas mulheres negras e tantas outras. Compreendemos o quanto elas falaram em seus ativismos, protestaram e questionaram, notamos também o quanto elas foram ouvidas. Agora, a voz que o movimento negro das mulheres clama para não continuar em silêncio é a voz da branquitude e dos privilegiados, a voz que precisa reconhecer seu prestígio, envergonhar-se da história de opressão de nosso país e gritar junto ao movimento negro que sim, vidas negras importam e que as ações antirracistas dos não negros são de fundamental importância para este reconhecimento numa prática transformadora.

A autonomia adquirida pelas feministas negras no ciberespaço obrigou os agentes dominantes a deixarem estas mulheres falar. Com a expansão do movimento negro feminino nas redes, outras mídias, instituições e indústrias não tiveram alternativa a não ser abrir espaço para as personalidades que representam a negritude e apoiar as causas dos movimentos negros. Sabemos que ainda há tentativas de silenciamento, e que os reconhecimentos nem sempre vêm pela quebra dos preconceitos, mas por interesses próprios, sociais e econômicos. No entanto, precisamos reconhecer as conquistas das mulheres negras brasileiras na agenda política social e o avanço que elas propõem na discussão. Cada vez mais, com o engajamento na Internet e seus ativismos, estas mulheres vêm sendo reconhecidas em outros âmbitos, que não só o virtual, ocupando lugares importantes mundialmente, pois a luta delas pode até começar a ganhar conhecimento na Internet, mas não fica restrita ao ciberespaço, ecoa nas mídias tradicionais e na sociedade real, mesmo no ano em que a população mundial foi obrigada a permanecer meses sem aglomerações, devido à pandemia. Diante de episódios grotescos de violência contra as vidas negras, estas mulheres levantaram as vozes na Internet e fora dela para fazer a população brasileira entender o porquê daquelas violências, compreender o racismo estrutural e a necessidade de não permitir que tais episódios se repitam, a partir da prática do antirracismo. 
Elas nos ensinam, com muito diálogo em suas redes sociais e muitas contextualizações teóricas e práticas, a como não continuarmos reproduzindo o que nos foi ensinado pela sociedade hegemônica; como não perpetuarmos falas e ações opressoras. As mulheres aqui estudadas enfatizam a importância de não sermos apenas contra o racismo, mas agirmos como antirracistas. Tal concepção não é recente, como nos mostram as primeiras ativistas negras, mas ganhou maior repercussão em 2020 e evidenciou como a ação antirracista por parte de todos se faz urgente.

\section{Referências}

AMARAL, Adriana; RECUERO, Raquel; MONTARDO, Sandra (org.). Blogs.com: Estudos sobre blogs e Comunicação. São Paulo: Momento editorial, 2009.

CARNEIRO, Sueli - Enegrecer o feminismo: a situação da mulher negra na américa latina a partir de uma perspectiva de gênero. Geledés, 2013.

GÉNOT, Luana. Textos extraídos do Instagram. 2020. Instagram: @luanagenot. Disponível em: https://www.instagram.com/luanagenot/?hl=pt-br. Acesso em: 15 jan. de 2021.

GONZALEZ, Lélia. Por um feminismo afro-latino-americano. In: HOLLANDA, Heloísa Buarque de. (org) - 1ed. Rio de Janeiro: Bazar do Tempo, 2020. p. 39-51.

HOOKS, Bell. E eu não sou uma mulher? Mulheres negras e feminismo. $1^{\text {a }}$ edição 1981. Tradução livre para a Plataforma Gueto. Janeiro 2014.

LEMOS, André. Ciber-socialidade: tecnologia e vida social na cultura contemporânea. Revista Logos - Comunicação e Universidade. Faculdade de Comunicação Social UERJ. Ano 4, número 6. 1997.

LEMOS, André.Ciber-Cultura-Remix. 2005. [s.l.: s.n.]. Disponível em: http://www.facom.ufba.br/ciberpesquisa/andrelemos/remix.pdf. Acesso em: 11 jan. de 2021.

MULLER, Tânia M. P.; CARDOSO, Lourenço (org.). Branquitude: estudos sobre a identidade branca no Brasil. Curitiba: Appris, 2017.

RECUERO, Raquel; BASTOS, Marco; ZAGO, Gabriela. Análise de Redes para Mídia Social. Porto Alegre: Sulina, 2015.

RIBEIRO, Djamila. Textos extraídos do Instagram. 2020. Instagram: @ djamilaribeiro1. Disponível em https://www.instagram.com/djamilaribeiro1/?hl=pt-br. Acesso em: 15 jan. de 2021. 
SOUZA, Lívia Natália. Textos extraídos do Instagram. 2020. Instagram: @livianataliapoeta.

em: https://www.instagram.com/livianataliapoeta/?hl=pt-br . Acesso em: 15 jan. de 2021.

Recebido em: 25/03/2021

Aceito em: 06/08/2021

\footnotetext{
${ }^{1}$ Em Black Reconstruction in America, 1860-1880 (1935), W. E. B. Du Bois conceituou "salário psicológico" para explicar a diferença salarial entre brancos e negros e a supremacia branca causada pelo colonialismo. Em 1988, Peggy McIntosh realizou uma pesquisa a fim de comprovar o privilégio branco e o seu impacto na sociedade. A pesquisa resultou em 46 privilégios da branquitude.

2 Termo utilizado por Tânia M. P. Müller e Lourenço Cardoso no livro Branquitude: estudos sobre a identidade branca no Brasil (2017).
} 